\title{
Carabid beetles (Coleoptera: Carabidae) and habitat fragmentation: a review
}

\author{
JARI NIEMELÄ \\ Department of Ecology and Systematics, PO Box 17, FIN-00014 University of Helsinki, Finland \\ e-mail: jari.niemela@helsinki.fi
}

\begin{abstract}
Key words. Carabids, conservation, dispersal, forests, habitat fragmentation, habitat heterogeneity, metapopulations, species
\end{abstract} richness, generalists, specialists

\begin{abstract}
I review the effects of habitat fragmentation on carabid beetles (Coleoptera, Carabidae) and examine whether the taxon could be used as an indicator of fragmentation. Related to this, I study the conservation needs of carabids. The reviewed studies showed that habitat fragmentation affects carabid assemblages. Many species that require habitat types found in interiors of fragments are threatened by fragmentation. On the other hand, the species composition of small fragments of habitat (up to a few hectares) is often altered by species invading from the surroundings. Recommendations for mitigating these adverse effects include maintenance of large habitat patches and connections between them. Furthermore, landscape homogenisation should be avoided by maintaining heterogeneity of habitat types. It appears that at least in the Northern Hemisphere there is enough data about carabids for them to be fruitfully used to signal changes in land use practices. Many carabid species have been classified as threatened. Maintenance of the red-listed carabids in the landscape requires species-specific or assemblage-specific measures.
\end{abstract}

\section{INTRODUCTION}

Destruction and fragmentation of habitats, overkill, introduction of alien species, and cascading effects of species extinctions have been labelled the "evil quartet", i.e. the four most detrimental, human-caused environmental changes affecting biodiversity (Pimm \& Gilpin, 1989). It is known that many species are negatively affected by habitat fragmentation, but lack of ecological knowledge of many taxonomic groups precludes detailed assessments of the magnitude and ecological meaning of these changes (McGeoch, 1998).

Assessment of the effects of fragmentation on wellknown taxa provides a useful insight that may guide further research and management recommendations. Such a well-known taxon could be the carabid beetles. This family is among the best known insect taxa in the Northern Hemisphere (Lindroth, 1961-69; Thiele, 1977; Desender et al., 1994; Lövei \& Sunderland, 1996; Niemelä, 1996; Niemelä et al., 2000), although not necessarily in the Southern Hemisphere (New, 1998). In addition to being abundant and speciose, these beetles are taxonomically and ecologically well-studied providing a good basis for the assessment of the effects of various human actions on their assemblages (Luff, 1996). Thus, carabids can provide the basis for taking the next step from mere after-the-fact judgements of human actions to making reliable predictions about the effects of such actions (Niemelä, 1996; Niemelä et al., 2000).

The aim of this non-exhaustive review is to address the following questions: (1) what do carabids teach us about the ecological effects of habitat fragmentation? (2) can carabids be used as indicators of fragmentation? and (3) are carabids themselves in need of conservation as a result of habitat fragmentation?

\section{HABITAT FRAGMENTATION AND CARABID ASSEMBLAGES}

\section{Effects of fragmentation on carabid assemblages}

Habitat fragmentation is the partitioning of a continuous habitat into many small remnants (Saunders et al., 1991; Haila, 1999; Debinski \& Holt, 2000). Sometimes the associated habitat loss is included in the concept of fragmentation. Here, I attempt to separate these two aspects and focus on the effects of fragmentation per se, i.e. isolation, size and configuration of the habitat remnants.

Studies on carabids have shown that habitat fragmentation influences assemblages by altering abundances and species richness. In a study comparing different sized fragments of coniferous forest surrounded by clearcut areas in Finland, Niemelä et al. (1988) found that although there were no differences in species richness, abundance of many species was higher in small $(<5 \mathrm{ha})$ than in large ( $>30 \mathrm{ha}$ ) forest remnants. This was most likely caused by changed environmental conditions in the small remnants making them more favourable for carabids.

In another study in Finland, species richness increased with decreasing size of forest patches surrounded by agricultural land (Halme \& Niemelä, 1993; Niemelä \& Halme, 1998). Small fragments (0.5-3.0 ha) had 18 species, large ones (9.6-21.5 ha) had 13 species, while continuous, unfragmented forest only had 11 species. There were more open-habitat species in the small fragments than in the large ones or continuous forest. This pattern was most likely attributed to the small fragments being more open and grassier, and thus more favourable for carabid species primarily residing in the surrounding grasslands. 
Similar results have been reported from England. Bauer (1989) studied carabid occurrence on limestone outcrops surrounded by peatbog, and reported that there was an inverse relationship between the size of the limestone outcrop and carabid species richness. Usher et al. (1993) found that the overall species richness of carabids in forest fragments surrounded by agricultural fields did not correlate with fragment size. In both studies, the pattern was caused by an increasing influx of species from the matrix into the fragments with decreasing remnant size. In addition, Usher et al. (1993) noted that the number of species was affected by the shape of the forest patch so that forest patches with high edge to area ratios contained more species because of higher invasion rate from the matrix.

Contrary to the above studies, a study in Canada showed that species richness of carabids increased with increasing forest fragment size (Burke \& Goulet, 1998). The smallest fragment with forest core area of $0.3 \mathrm{hec}$ tares had only two carabid species while there were 16-17 species in fragments $>30$ ha and 22 species in continuous forest. However, isolation confounded the results so that the lowest species richness was found in small, isolated fragments, while less isolated small fragments had a species richness comparable to that in large fragments.

Effects of fragmentation are manifested at the species level. In the Finnish study, many forest species were absent from the small fragments, probably because of unsuitable habitat (Halme \& Niemelä, 1993). Furthermore, the most specialized forest species occurred only in the continuous forest (e.g., Carabus glabratus Paykull, C. violaceus L.). These specialists are flightless, which probably hampers their movements across grassland between forest patches. Radio-tracking has shown that forest species are reluctant to cross open habitat (Riecken \& Raths, 1996). Similarly, Bauer (1989) and Usher et al. (1993) reported that specialist species of the fragmented habitat type respond positively to fragment size so that their species richness increased with increasing fragment size.

A study from Australia using data from before and after fragmentation of Eucalyptus forest showed that carabid species richness was not affected by fragment size (Davies \& Margules, 1998). Three of the eight abundant species responded to remnant size: one was most abundant in small remnants ( $0.25 \mathrm{ha})$, one was most abundant in large remnants (3.1 ha), and one was less abundant in medium-sized fragments (0.88 ha). In addition to fragment size, isolation was studied. Only two of the eight abundant species responded to isolation of the remnants by declining in population size. These results indicate that carabid responses to fragmentation are variable and species-specific. Most species were habitat generalists and not sensitive to habitat fragmentation, while some were favoured, and some suffered from fragmentation (Davies \& Margules, 1998).

The reviewed papers show that there are basically two ways of finding out how carabids are affected by frag- mentation. First, one can compare existing fragments with a non-fragmented control site assuming that carabid assemblages have been similar in the fragment and control site before fragmentation. Second, stronger evidence can be derived from monitoring field manipulations in which remnants of various sizes have been created by fragmenting a continuous habitat. This so called BACI approach (Before-After-Control-Impact, Underwood, 1991) is the recommended one because one can control for the environmental variation between sites and year-toyear fluctuations in conditions. However, the only study using this method is that of Davies \& Margules (1998).

The above studies also show that simply counting the number of species provides little information about specific effects of fragmentation. Species richness used as a measure of biological conservation value may be misleading because disturbances may favour widespread and abundant generalists leading to increased species richness. In contrast, analysing the responses of single species is more likely to provide an understanding of the processes that lead to extinction or persistence in fragmented landscapes (Davies \& Margules, 1998). In addition, "rarity values" or "rarity scores" of sites (or species assemblages) can be used in combination with species richness to provide a measure of the conservation value of a site (Blake et al., 1996; Eyre et al., 1996).

\section{Carabid metapopulations and dispersal in fragmented landscapes}

Species that occur in a fragmented landscape with subpopulations that are connected to each other by dispersal, i.e. have a metapopulation structure, may be better buffered against local extinctions than species living in discrete sub-populations. Although proper tests of whether or not carabid populations are structured as metapopulations are scarce, there are a few studies indicating that this may be the case in certain situations. Forest carabids occupying hedges and small forest patches appear to form metapopulations in an agricultural landscape (Burel \& Baudry, 1995). These forest-dwellers have poor dispersal ability and their survival depends on connections and short distances between suitable patches.

Dispersal ability is important for the survival of carabid species in fragmented landscapes (den Boer, 1985). For instance, there is no or a very weak relationship between size of heathland patches and number of good dispersers occupying them, while the number of poor dispersers increases with patch size (de Vries, 1994, 1996). This result indicates that good dispersers are able to maintain populations in the small and isolated patches through recolonisation of empty patches, whereas poor colonisers are not able to do so.

The importance of dispersal for the survival of species in a fragmented landscape is supported by the experimental introductions of the heathland carabid Pterostichus lepidus Leske to empty heathland patches (de Vries, 1996). The species is able to reproduce in the fragments (1.3-3.2 ha), and therefore, its absence from them is probably caused by its failure to colonise them. Thus, for such a species the continued fragmentation of the heath- 
land in north-western Europe may pose serious problems (de Vries, 1996).

Because of their "earthbound" way of life carabids may in general be poorer dispersers than, for instance, rove beetles (Staphylinidae). Better flight ability may explain the greater numbers of staphylinids than carabids on limestone outcrops surrounded by peat bog in England (Bauer, 1989). Thus, carabids may be more vulnerable to habitat fragmentation than the better dispersing staphylinids.

\section{Implications for landscape management}

Work on the effects of habitat fragmentation on carabids has several implications for landscape management aimed at population survival. First, increasing similarity of habitat patches (i.e. homogenisation of landscapes) homogenises species assemblages among habitat patches. It has been shown that intrusion of species from the matrix into the focal patch increases with habitat similarity between the focal patch and the surrounding matrix (Webb \& Hopkins, 1984; Bauer, 1989; Halme \& Niemelä, 1993). However, it is important to note that the extent to which species leave their native habitat and disperse to other habitats depends on their habitat preferences (Usher et al., 1993). For instance, some forest generalists (i.e., occur in several forest types) use hedgerows as dispersal routes, and bushes as "stepping stones" when moving around in a forest-agricultural landscape (Burel \& Baudry, 1994), while forest specialists (i.e., restricted to a certain type of forest) are reluctant to disperse in this way (Burel, 1989). The former species are better able to disperse and survive in a fragmented forest landscape, where hedgerows and bushes may be the prevalent "forest" type than are strict forest species. Thus, the similarity between the matrix and the focal habitat (i.e., high quality of the matrix) enhances dispersal between fragments, but it makes the focal patches more vulnerable to invasion by generalist species dwelling in the matrix (Halme \& Niemelä, 1993). Although it is often desirable to minimise invasion from surroundings into the focal patch, covering the surroundings by concrete, as half-seriously suggested by Bengtson \& Enckell (1983), may not be a viable management option. Thus, these results imply that in order to maintain diverse species assemblages in a landscape it is important to maintain heterogeneity of habitats.

Second, and related to the previous point, dispersal of habitat specialists may be enhanced by maintenance of connectivity, e.g. corridors of hedgerows or other linear tree habitats for forest species. For instance, markrecapture experiments showed that Calathus rotundicollis Dejean will move along a $14 \mathrm{~m}$-wide hedgerow but will not enter a field (Plat et al., 1995). Furthermore, Charrier et al. (1997) noted that marked Abax parallelepipedus Piller \& Mitterpacher mainly stays within wooded habitats (forest or 3-5 m wide hedgerows). Some beetles left the forest to enter the surrounding fields, but tended to stay within the field margins shaded by trees. Thus, connecting habitat patches, such as forest stands, with wooded corridors may increase the survival of forest species in a predominantly agricultural landscape.
Hedges may have surprisingly rapid effects on local carabid distribution. Fournier \& Loreau (1999) showed that even a 2-year old and rather low $(2 \mathrm{~m})$ hedge has a higher species richness than the surrounding agricultural land. Furthermore, several species were restricted to the hedge and were not found in the surrounding fields. In contrast, Gruttke (1994) found that only two species (Carabus nemoralis Müller and Notiophilus palustris Duftschmid) dispersed along a ten-year old hedgerow in a cultivated landscape. Small trees $(3-4 \mathrm{~m})$ and gaps in the hedge may account for the absence of other forest species from the hedgerow. On the other hand, these trees were almost twice as tall as those reported by Fournier \& Loreau (1999) to have positive effects on carabid species richness.

In addition to tree height, tree species composition may affect carabid dispersal along hedges. Šustek (1992) noted that hedgerows consisting of native tree species are able to maintain a higher abundance of forest species than are hedgerows of introduced tree species. Thus, it may be that the effects of hedges are landscape-specific and may depend on, for instance, the land use history and intensity. More research is needed to distinguish between these possibilities.

Third, even highly human-modified connections may be of importance for carabids. For instance, Pterostichus lepidus, Harpalus servus Duftschmid and Cymindis macularis Fischer von Waldheim, which live in open grassland, disperse along roadsides in Holland indicating that road verges can act as dispersal corridors (Vermeulen, 1994). Vermeulen (1993) suggested that corridors of heath vegetation could be established along roads to facilitate dispersal of carabids between heathland patches, and thus enhance their survival in the fragmented heathland landscape. Furthermore, for some species linear structures may function as habitat where reproduction takes place, not just dispersal. For instance, species associated with early successional stages of vegetation use sandy roadside verges both as dispersal corridors and population refugia (Eversham \& Telfer, 1994).

Fourth, species richness of habitat specialists increases with the area of the suitable habitat patch. For instance, number of woodland carabid species increased with size of forest patches surrounded by fields (Usher et al., 1993; Halme \& Niemelä, 1993). In addition to small patches losing specialist species, they are vulnerable to invasion by species from outside. Bauer (1989) noted that the number of species invading a small limestone patch ( $<10 \mathrm{~m}$ in radius) from the surrounding peatland could equal the number of resident limestone species. Furthermore, Usher et al. (1993) reported that the number of species was affected by the shape of the forest patch so that forest patches with higher edge to area ratios contained more species because of a high invasion rate from the matrix.

The above studies show that fragment size is important, but how big should a habitat patch be in order to maintain specialist species of the interior habitat? Halme \& Niemelä (1993) showed that even forest patches as large as 
20 hectares surrounded by grasslands did not host intact forest carabid communities. Furthermore, the largest forest patches surrounded by fields studied by Usher et al. (1993) were 10 hectares and they were invaded by species from the matrix. Thus, because of habitat changes in small fragments leading to extinction of interior specialists and invasion of matrix species, the minimum size of a patch that maintains an intact assemblage of interior carabids is at least tens of hectares. Even larger areas may be required as it has been estimated that a forest area of $500-1000$ hectares is required for maintaining an intact terrestrial invertebrate assemblage in the Amazonian rain forest (Didham, 1997).

Fifth, isolation alone has been noted to affect carabid species richness and species composition of habitat patches. There was a positive correlation between carabid species richness in small patches of cultivated fields $(<4.3 \mathrm{ha})$ and the area of farmland within a distance of 1-2 km from the focal field (Kinnunen et al., 1996). However, Usher et al. (1993) reported that isolation did not affect species richness of woodland carabids in forest fragments, but did decrease species number of spiders. Thus, minimising isolation appears to be a good goal for maintenance of invertebrates of the focal habitat in the landscape.

Sixth, the knowledge of species-specific dispersal ability and habitat preferences (e.g., Thiele, 1977) makes carabids useful indicators of the severity of habitat fragmentation. The presence of habitat specialists with good dispersal ability (i.e., high probability of recolonisation) would indicate suitability of the habitat patch, but not whether the patch is large enough for long-term persistence of the population. The presence of habitat specialists with poor dispersal ability (i.e., low probability of recolonisation) would indicate that the habitat is suitable and the patch is large enough for long-term persistence of populations or close enough to other patches to be recolonised even by poorly dispersing species. However, species-specific metapopulation dynamics including extinctions and recolonisations need to be considered, and these can be traced only by long term studies.

To conclude, fragmentation studies on carabids indicate that in order to maintain the characteristic fauna of a habitat type the patches to be preserved should be as large as possible. Connectivity between habitat patches appears to enhance population survival, but care has to be taken not to homogenise the landscape through increased similarity between the focal habitat patches and the matrix. Furthermore, the shape of focal habitat patches is critical. It should be as round as possible to minimise the proportion of edge, and thereby the number of species invading from the surroundings (Usher et al., 1993).

\section{CLOSING THE ACT: CONSERVATION OF CARABIDS IN FRAGMENTED LANDSCAPES}

In addition to being indicators of fragmentation, carabids themselves may be targets for conservation efforts because many species are threatened by habitat fragmentation. For instance, Desender \& Turin (1989) list
142 carabid species that are endangered in western Europe (Denmark, Netherlands, Belgium and Luxembourg) representing as much as one third of the carabid fauna in these countries. At least some of them are threatened because of habitat fragmentation.

An illustrative example of a carabid species declining in various parts of Europe partly because of fragmentation is Laemostomus terricola Herbst. In central-northern Europe the species occurs in rabbit burrows and is declining probably due to destruction and fragmentation of suitable habitat for rabbits (Gruttke, 1994). However, in Finland the species was strictly associated with human dwellings, such as cellars, bakeries, warehouses before its disappearance due to improved hygiene.

Some fragmented and human-influenced habitats may be favourable for carabids. Roadsides appear to be especially suitable for threatened carabids associated with early successional habitats, such as sandy grassland. Vermeulen (1993) lists 23 stenotopic heathland carabid species from sandy road verges in the Netherlands. These species make up half of the 45 carabid species considered as characteristic of sandy, open habitats in the country. Nine of these 23 species are threatened (Desender \& Turin, 1989). Also in England, roadsides are favoured by carabids. Of the 66 carabid species found on roadside verges at least 22 are stenotopic heathland species, and 19 are nationally or locally threatened (Eversham \& Telfer, 1994). Frequently disturbed road verges may contribute to the survival of species whose original habitats are being destroyed and fragmented, and whose environmental requirements are not easily met with conventional nature reserve management (Eversham \& Telfer, 1994).

In addition to road verges, some other dry, open and human-created habitats have proved to be suitable habitats for rare carabids that are threatened due to fragmentation of their original habitat. Desender \& Bosmans (1998) reported from Belgium that set-aside fields on sandy soils (dominated by grasses such as Holcus spp., Festuca spp.) with patches of bare soil host as many as 53 carabid species including 11 species listed as endangered in the study region. Many of these species are adapted to unstable conditions of dry grasslands on sandy soils, and have thus good dispersal ability. It appears that if suitable habitat is created and maintained in the landscape, these species quite easily colonise the patches. Desender \& Bosmans (1998) suggested that conversion of agricultural fields to nutrient-poor and dry grasslands has great potential for maintaining and enhancing populations of many rare and threatened carabid species. However, the sites require constant management in order to stay open and treeless.

A good example of a species requiring habitat maintained by regular management is Carabus nitens $\mathrm{L}$. The species was once common in Europe's large heathland areas, but fragmentation and disappearance of heathlands means the survival of $C$. nitens is threatened in many parts of Europe (Assmann \& Janssen, 1999). The species inhabits Erica and Calluna dominated heathlands, which are disappearing due to cultivation and increased $\mathrm{NH}_{\mathrm{x}}$ depositions promoting the growth of grasses that dramati- 
cally change the heathland habitat. In addition to being absent from the grassy heathland sections, the species is not found in several suitable patches of heathland in the Lüneburger Heide in northern Germany. This is probably because of its inability to recolonise patches from which the species has disappeared (Assmann \& Janssen, 1999). Measures to improve the survival probability of C. nitens include restoration of the suitable early-stage heathland habitat, creation of habitat links between suitable heathland patches and reintroductions of beetles to suitable habitat patches (see also Usher, 1992).

In addition to heathlands, bogs are disappearing in many parts of Europe. Spitzer et al. (1999) showed that an isolated peat bog in the Czech Republic has a unique carabid fauna, and recommended that the bog be kept open by appropriate management procedures in order to maintain the characteristics of the habitat.

Some threatened carabid species occur in habitats that are especially vulnerable to fragmentation. An example is the rare Agonum mannerheimii Dejean, which requires moist patches in old-growth boreal forest (Niemelä et al., 1987; Lindelöw, 1990). If such a patch is destroyed due to forestry practices, the species disappears (Niemelä et al., 1993).

In conclusion, the distribution of carabids reflects human-caused environmental changes, such as habitat fragmentation. As the group is well-known in the northern Hemisphere (Thiele, 1977; Lindroth 1961-69), responses of species to environmental changes can be explained in terms of their biology. In certain parts of the world, however, this group of insects is less well known. For example, in Australia the use of the carabid fauna in environmental assessment is restricted because of the taxonomic impediment, and lack of ecological and faunistic information (New, 1998). The same is true for carabids in South Africa, where many abundant species in an Afromontane study could only be identified to morphospecies level (Kotze \& Samways, 1999). These, and many other countries, still have to catch up to the level of basic taxonomy and biology now existing in northern Europe. Also, the general usefulness of carabids in signalling land-use changes has not been studied everywhere (New, 1998). The knowledge base existing in the Northern Hemisphere could be used as a framework to test if carabid assemblages respond to environmental changes in similar ways in other parts of the world. This is the main thrust of a global project initiated recently (Niemelä et al., 2000).

The wealth of information on carabids provides an opportunity to use them to signal and predict changes in the environment caused by, e.g., fragmentation. As carabids can be easily and rather reliably collected using pitfall traps, standardised monitoring of environmental changes using carabids may be possible (Niemelä et al., 2000). However, as emphasised by Usher (1992) the sometimes contradictory responses of various taxonomic groups, such as plants and carabids, to environmental changes underlines the importance of considering the conservation of the various taxonomic groups in their own right.

ACKNOWLEDGEMENTS. Johan Kotze is thanked for critical comments. This is a contribution from the ECOPLAN research project funded by the Finnish Biodiversity Research Programme.

\section{REFERENCES}

AsSMANN T. \& JANSSEN J. 1999: The effects of habitat changes on the endangered ground beetle Carabus nitens (Coleoptera: Carabidae). J. Insect Conserv. 3: 107-116.

BAUER L.C. 1989: Moorland beetle communities on limestone "habitat islands". I. Isolation, invasion and local species diversity in carabids and staphylinids. J. Anim. Ecol. 58: 1077-1098.

Bengtson S. \& Enckell P.H. 1983: Preface. Oikos 41: 296-298.

Blake S., Foster G.N., Fischer G.E.J. \& Ligertwood G.L. 1996: Effects of management practices on the carabid fauna of newly established wildflower meadows in southern Scotland. Ann. Zool. Fenn. 33: 139-147.

BOER DEN P.J. 1985: Fluctuations of density and survival of carabid populations. Oecologia 67: 322-330.

BUREL F. 1989: Landscape structure effects on carabid beetles spatial patterns in western France. Landscape Ecol. 2: 215-226.

BUREL F. \& BAUdRY J. 1994: Reaction of ground beetles to vegetation changes following grassland dereliction. Acta Oecol. 15: 401-405.

BUREL F. \& BAUdRY J. 1995: Species biodiversity in changing agricultural landscapes: a case study in the Pays d'Auge, France. Agric. Ecosyst. Envir. 55: 193-200.

Burke D. \& Goulet H. 1998: Landscape and area effects on beetle assemblages in Ontario. Ecography 21: 472-479.

Charrier S., Petit S. \& Burel F. 1997: Movements of Abax parallelepipedus (Coleoptera, Carabidae) in woody habitats of a hedgerow network landscape: a radio-tracing study. Agric. Ecosyst. Envir. 61: 133-144.

Davies K.F. \& Margules C.R. 1998: Effects of habitat fragmentation on carabid beetles: experimental evidence. J. Anim. Ecol. 67: 460-471.

Debinski D.M. \& Holt R.D. 2000: A survey and overview of habitat fragmentation experiments. Conserv. Biol. 14: 342-355.

Desender K. \& Bosmans R. 1998: Ground beetles (Coleoptera, Carabidae) on set-aside fields in the Campine region and their importance for nature conservation in Flanders (Belgium). Biodivers. Conserv. 7: 1485-1493.

Desender K., Dufrene M., Loreau M., Luff M.L. \& Maelfait J.P. (eds) 1994: Carabid Beetles: Ecology and Evolution. Kluwer Academic Publishers, Dordrecht, 474 pp.

Desender K. \& TuRin H. 1989: Loss of habitats and changes in the composition of the ground and tiger beetle fauna in four west European countries since 1950 (Coleoptera: Carabidae, Cicindelidae). Biol. Conserv. 48: 277-294.

DiDHAM R.K. 1997: The influence of edge effects and forest fragmentation on leaf litter invertebrates in central Amazonia. In Laurance W.F. \& Bierregaard R.O.Jr. (eds): Tropical Forest Remnants: Ecology, Management, and Conservation of Fragmented Communities. The University of Chicago Press, Chicago \& London, pp. 55-70.

Eversham B.C. \& Telfer M.G. 1994: Conservation value of roadside verges for stenotopic heathland Carabidae: corridors or refugia? Biodivers. Conserv. 3: 538-545. 
Eyre M.D., Lott D.A. \& Garside A. 1996: Assessing the potential for environmental monitoring using ground beetles (Coleoptera, Carabidae) with riverside and Scottish data. Ann. Zool. Fenn. 33: 157-64.

Fournier E. \& Loreau M. 1999: Effects of newly planted hedges on ground-beetle diversity (Coleoptera, Carabidae) in an agricultural landscape. Ecography 22: 87-97.

GRUTTKE H. 1994: Investigations on the ecology of Laemostenus terricola (Coleoptera, Carabidae) in an agricultural landscape. In Desender K., Dufrêne M., Loreau M., Luff M.L. \& Maelfait J.-P. (eds): Carabid Beetles, Ecology and Evolution. Kluwer Academic Press, Dordrecht, pp. 145-151.

HaILA Y. 1999: Islands and fragments. In Hunter M.L.Jr. (ed.) Maintaining Biodiversity in Forest Ecosystems. Cambridge University Press, Cambridge, pp. 234-264.

Halme E. \& Niemelä J. 1993: Carabid beetles in fragments of coniferous forest. Ann. Zool. Fenn. 30: 17-30.

Kinnunen H., Järvelärnen K., Pakkala T. \& Tiannen J. 1996: The effect of isolation on the occurrence of farmland carabids in a fragmented landscape. Ann. Zool. Fenn. 33: 165-171.

Kotze J. \& Samways M. 1999: Invertebrate conservation at the interface between the grassland matrix and natural Afromontane forest fragments. Biodivers. Conserv. 8: 1339-1363.

LINDELÖW $\AA$. 1990: Habitat preferences and seasonal activity of Agonum mannerheimii (Coleoptera, Carabidae) in Swedish spruce bog. Entomol. Tidskr. 111: 163-166 (in Swedish, English abstr.).

LindRoth, C.H. 1961-1969: The ground-beetles of Canada and Alaska, parts 1-6. Opuscula Entomologica, supplementa XX, XXIV, XXIX, XXXIII, XXXIV, XXXV: 1-1192.

LuFF M.L. 1996: Use of carabids as environmental indicators in grasslands and cereals. Ann. Zool. Fenn. 33: 185-196.

Löver G.L. \& SunderLand K.D. 1996: Ecology and behavior of ground beetles (Coleoptera: Carabidae). Annu. Rev. Entomol. 41: 231-256.

McGeoch M.A. 1998: The selection, testing and application of terrestrial insects as bioindicators. Biol. Rev. 73: 181-201.

NEW T. 1998: The role of ground beetles (Coleoptera: Carabidae) in monitoring programmes in Australia. Ann. Zool. Fenn. 35: 163-171.

NiemelÄ J. (ed.) 1996: Population biology and conservation of carabid beetles. Ann. Zool. Fenn. 33: 1-241.

Niemelä J. \& Halme E. 1998: Effects of forest fragmentation on carabid assemblages in the urban setting: implications for planning and management. In Breuste J., Feldmann H. \& Uh1mann O. (eds): Urban Ecology. Springer Verlag, Berlin, pp. 692-695.

Niemelä J., Haila Y., Halme E., Lahti T., Pajunen T. \& PuntTILA P. 1988: The distribution of carabid beetles in fragments of old coniferous taiga and adjacent managed forest. Ann. Zool. Fenn. 25: 107-119.

Niemelä J., Haila Y., Halme E., Pajunen T., Punttila P. \& TuKrA H. 1987: Habitat preferences and conservation status of Agonum mannerheimii Dej. in Häme, southern Finland. Not. Entomol. 67: 175-179.

Niemelä J., Kotze J., Ashworth A., Brandmayr P., Desender K., New T., Penev L., Samways M. \& Spence J. 2000: The search for common anthropogenic impacts on biodiversity: a global network. $J$. Insect Conserv. 4: 3-9.

Niemelä J., Langor D. \& Spence J.R. 1993: Effects of clear-cut harvesting on boreal ground-beetle assemblages (Coleoptera: Carabidae) in western Canada. Conserv. Biol. 7: 551-561.

PImm S.L. \& GilpIN M.E. 1989: Theoretical issues in conservation biology. In Roughgarden J., May R.M. \& Levin S.A. (eds): Perspectives in Ecological Theory. Princeton University Press, Princeton, pp. 287-305.

Plat S., Kunvenhoven P. \& van Dirk T.S. 1995: Hedgerows: suitable corridors for ground dwelling forest carabid beetles? Proceedings of the Section Experimental and Applied Entomology of the Netherlands Entomologicval Society (N.E.V.) 6: $73-75$.

RIECKEN U. \& RATHS U. 1996: Use of radio telemetry for studying dispersal and habitat use of Carabus coriaceus L. Ann. Zool. Fenn. 33: 109-116.

Saunders D.A., Hobb R.J. \& Margules C.R. 1991: Biological consequences of ecosystem fragmentation: a review. Conserv. Biol. 5: 18-32.

SPITZER K., BEZDĚK A. \& JARoš J. 1999: Ecological succession of a relict Central European peat bog and variability of its insects biodiversity. J. Insect Conserv. 3: 97-106.

Sustek Z. 1992: Changes in the representation of carabid life forms along an urbanisation gradient (Coleoptera, Carabidae). Biológia (Bratislava) 47: 417-430.

ThIele H.-U. 1977: Carabid Beetles in Their Environments. Springer Verlag, Berlin, $369 \mathrm{pp}$.

UNDERWOOD A.J. 1991: Beyond BACI: Experimental designs for detecting human environmental impacts on temporal variations in natural populations. Aust. J. Mar. Freshw. Res. 42: $596-87$.

UsHer M.B. 1992: Management and diversity of arthropods in Calluna heathland. Biodivers. Conserv. 1: 63-79.

Usher M.B., Field J. \& BeDFord S. 1993: Biogeography and diversity of ground-dwelling arthropods in farm woodlands. Biodivers. Letts. 1: 54-62.

VeRMEULEN H.J.W. 1993: The composition of the carabid fauna on poor sandy road-side verges in relation to comparable open areas. Biodivers. Conserv. 2: 331-350.

VERMEULEN H.J.W. 1994: Corridor function of a road verge for dispersal of stenotopic heathland ground beetles Carabidae. Biol. Conserv. 69: 339-349.

VRIES DE H.H. 1994: Size of habitat and presence of ground beetle species. In Desender K., Dufrêne M., Loreau M., Luff M.L. \& Maelfait J.-P. (eds): Carabid Beetles, Ecology and Evolution. Kluwer Academic Press, Dordrecht, pp. 253-259.

VRIES DE H.H. 1996: Metapopulation structure of Pterostichus lepidus and Olisthopus rotundatus on heathland in the Netherlands: the results from transplant experiments. Ann. Zool. Fenn. 33: 77-84.

Webi N.R. \& Hopkins P.J. 1984: Invertebrate diversity on fragmented Calluna heathland. J. Appl. Ecol. 21: 921-933.

Received August 15, 2000; revised October 5, 2000; accepted October 30, 2000 